NBER WORKING PAPER SERIES

\title{
AVERTING REGULATORY ENFORCEMENT: EVIDENCE FROM NEW SOURCE REVIEW
}

\author{
Nathaniel Keohane \\ Erin T. Mansur \\ Andrey Voynov \\ Working Paper 13512 \\ http://www.nber.org/papers/w13512
}

\author{
NATIONAL BUREAU OF ECONOMIC RESEARCH \\ 1050 Massachusetts Avenue \\ Cambridge, MA 02138 \\ October 2007
}

We thank Jim Bushnell and Catherine Wolfram for many helpful discussions. We also thank Catherine Wolfram for data on firms' financial statistics. Michael Greenstone and Ken Chay are thanked for data on attainment counties. We also thank two anonymous referees and seminar participants at Yale University, Rice University, University of Houston, Texas A\&M University, Resources for the Future, Dartmouth College, and NBER. The views expressed herein are those of the author(s) and do not necessarily reflect the views of the National Bureau of Economic Research.

(C) 2007 by Nathaniel Keohane, Erin T. Mansur, and Andrey Voynov. All rights reserved. Short sections of text, not to exceed two paragraphs, may be quoted without explicit permission provided that full credit, including $(\mathrm{C}$ notice, is given to the source. 
Averting Regulatory Enforcement: Evidence from New Source Review

Nathaniel Keohane, Erin T. Mansur, and Andrey Voynov

NBER Working Paper No. 13512

October 2007

JEL No. L51,L94,Q52,Q58

\section{ABSTRACT}

This paper explores firms' response to regulatory enforcement. New Source Review, a provision of the Clean Air Act, imposes stringent emissions limitations on significantly modified older power plants. In 1999, the EPA sued owners of 46 plants for NSR violations. We study how electricity companies respond to both the perceived threat of future action, and the action itself. A discrete choice model estimates plants likelihood of being named in lawsuits increases with large historic emissions and investments. On the eve of the lawsuits, emissions at plants with a one standard deviation greater probability of being sued fell approximately ten percent.

Nathaniel Keohane

Yale University, School of Management 135 Prospect St.

Box 208200

New Haven, CT 06520-8264

nathaniel.keohane@yale.edu

Erin T. Mansur

Yale School of Management

135 Prospect Street

P.O. Box 208200

New Haven, CT 06520-8200

and NBER

erin.mansur@yale.edu
Andrey Voynov

Yale School of Forestry and Environmental Studies

205 Prospect Street

New Haven, CT 06511

andrey.voynov@aya.yale.edu 


\section{Introduction}

This paper uses data from the U.S. electric power industry to explore the strategic responses of regulated firms to government enforcement. We focus on the provisions of the Clean Air Act that impose stringent emissions limitations on new sources and extend these new-source limits to aging power plants that undergo substantial modification. In November 1999, the Environmental Protection Agency (EPA) announced a sweeping enforcement action against 24 electric power plants. The agency announced additional lawsuits in the following year, bringing the total to 46 plants owned by nine utilities. The lawsuits charged that the plants' parent utilities had failed to seek regulatory approval for major modifications that should have been reviewed by the agency to determine whether they triggered the more stringent emissions limits applicable to new sources.

These "New Source Review" (NSR) regulations offer a valuable test case for studying how the threat of enforcement affects the behavior of regulated firms, because we can identify precisely when that threat became salient. Although the law had been in place for decades, it was never vigorously enforced. In the sole prominent enforcement action brought by the EPA prior to the period we study, the court handed down a ruling that strongly favored the industry. Before 1998, therefore, there was little to make the industry concerned about the threat of a regulatory crackdown. In that year, however, the EPA announced a more aggressive stance. The industry did not know in advance which plants would be named in the suits; the ambiguity over how the law would be interpreted allowed the EPA considerable scope in deciding whom to target. But there was widespread expectation by the end of 1998 that the EPA was about to enforce the law more vigorously.

In this paper, we explore how electric utilities responded to the perceived threat of future action, as well as to the lawsuits themselves. Our measure of "response" focuses on plants' emissions, since those were not only a known trigger of regulatory action but also the source of concern that motivated the regulations in the first place. Of course, power plants were not equally vulnerable to the imminent enforcement. For example, power plants that had 
made major capital investments in previous years might have fallen under greater regulatory scrutiny.

To distinguish among power plants in the severity of the threat, therefore, we first investigate the determinants of the EPA's choice of which plants to name in the lawsuit: in particular, we want to determine which historic, exogenous factors firms might have expected to have influenced the likelihood of their plants being named in a lawsuit. In line with the official agency stance, we find that the probability of enforcement action was higher at plants with large increases in emissions and large capital investments (excluding investments in pollution control equipment) over the previous fifteen years. However, the EPA was also more likely to target plants owned by large utilities.

In the second part of our analysis, we use the estimated coefficients from our model of the agency's choice to construct a predicted enforcement probability for each plant. Using a panel data set of monthly plant-level emissions from January 1996 to December 2000, we run a fixed effects regression of emissions on this measure of the perceived threat during the threat of enforcement period. We also examine how the emissions of plants named in lawsuits changed after the lawsuits were announced.

Here we focus exclusively on power plants that were required to participate in the first phase of the sulfur dioxide $\left(\mathrm{SO}_{2}\right)$ allowance market created by Title IV of the 1990 Clean Air Act Amendments. These were the oldest and dirtiest plants, and therefore among the most likely to be sued; moreover, they faced a constant regulatory regime over the period of interest, since Phase I lasted from 1995 through 1999. (In contrast, plants that entered the allowance market only in Phase II, starting in 2000, experienced a sharp change in air pollution regulation at just the same time as EPA was stepping up its enforcement.) We find strong evidence that firms sought to avert enforcement. Plants that were more likely to be sued show greater reductions in emissions, even controlling for plant and month-year fixed effects. On the eve of the lawsuits, emissions at plants with a one standard deviation greater probability of being sued fell approximately ten percent. The plants named in lawsuits also 
reduced emissions: on average, their emissions fell 18 percent.

The third part of our analysis returns to the model of enforcement and asks whether firms' evasive actions did result in lowering the probability of being sued. We find that a plant's current emissions helped predict whether it was named in the EPA's lawsuits, controlling for the potential endogeneity of emissions and enforcement. This suggests that power plants had reasonable grounds to change their behavior after the threat became known, but before the EPA announced its lawsuits. For a subset of data, we also report the results of a three-stage least squares model that tests the robustness of our findings.

The paper proceeds as follows. The next section reviews related literature. Section 3 discusses the history of New Source Review regulation, setting the stage for our subsequent analysis. Section 4 models regulators' decision of which power plants to name in the lawsuits. In particular, we examine whether-based on historic actions at a power plant - a firm might expect to be sued. In section 5, we examine whether threatened firms attempted to avert enforcement by reducing emissions. Section 6 examines whether regulators incorporated these reduced emissions in their decision of which plants to name in lawsuits. The final section offers conclusions.

\section{Related Literature}

Our paper relates to several existing strands of the economics literature. First, our paper is closely related to the literature on self-regulation, which examines when a firm (or a group of firms) self-regulates in order to preempt regulatory action. Maxwell et al. (2000) develop a theoretical model of firms that deter political action through voluntary restraints. Using toxic release data, they find evidence that increased regulatory threat induces firms

to reduce emissions. Corporations' environmental management systems tend to be more comprehensive when there are higher compliance costs, public pressure, or liability threats (Khanna and Anton, 2002). Anton et al. (2004) find that more comprehensive systems are 
associated with lower emissions of toxics. However, the theoretical literature shows that self-regulation does not necessarily improve welfare. ${ }^{1}$ Lyon and Maxwell (2004) provide a detailed discussion of the general literature on regulatory threat.

Our focus on the determinants of enforcement complements previous work on regulatory enforcement and its effects on compliance. In a study of the pulp and paper industry, Magat and Viscusi (1990) find that more strenuous enforcement (as measured by the frequency of inspections) increases subsequent compliance. Bartel and Thomas (1985) conclude that more frequent inspections increases compliance with workplace safety regulations, but find little evidence that compliance drives enforcement decisions.

More recent empirical analyses of enforcement have taken explicit account of the potential endogeneity between enforcement and the behavior of regulated firms (Gray and Deily 1996; Laplante and Rilstone 1996; Eckert 2004). For example, Gray and Deily use a simultaneous equations model to account for endogeneity; they find that enforcement of air pollution regulation induces compliance among regulated steel mills, while compliance averts enforcement. We address the same endogeneity issues here, using predicted enforcement probabilities as an instrument for actual enforcement decisions. A key difference, however, is our interest on how the threat of enforcement changes behavior prior to the enforcement decision itself. In other words, we also use the predicted probability of enforcement as the actual independent variable of interest in predicting behavior - a measure of the degree of threat, rather than a way of getting around endogeneity. ${ }^{2}$

In its topical focus, this paper is heir to a long line of literature on so-called "vintagedifferentiated regulations" or VDRs, of which NSR is one of the most prominent examples. ${ }^{3}$ Economists have long bemoaned the perverse investment incentives created by programs that differentially affect old and new sources of pollution. The underlying legislation that gave rise to NSR was the 1970 and 1977 Clean Air Act Amendments, which imposed stringent standards on new sources of emissions while exempting or "grandfathering" existing sources. These new-source standards led electric utilities to extend the operating lives of old power 
plants, delaying the construction of new ones (Nelson 1984; Maloney and Brady 1988; Nelson et al. 1993).

In a recent paper, Bushnell and Wolfram (2006) [henceforth BW] identify a second perverse effect of VDRs: regulated firms are discouraged from undertaking investments that would improve the operating efficiency of existing units, in the fear that doing so will trigger enforcement. Consistent with this view, List et al. (2004) find that NSR slowed modification rates at industrial facilities in sectors other than electric power. To probe the extent of this distortion, BW examine NSR enforcement in the electric power industry, as we do, but ask a slightly different question: Did stepped-up enforcement by the EPA affect plant-level heat rates or expenditures on capital investment and operation \& maintenance expenditure? They find some evidence of an effect on investment, but no evidence of an effect on O\&M expenditure or heat rates.

Because BW and our paper use similar data to ask closely related questions, it is worth pointing out how the two studies diverge. First, BW are interested in vintage-differentiated regulation per se, and how enforcement of such regulations distorts investment decisions. In contrast, the motivation for our analysis is the strategic response of regulated firms to the threat of enforcement. As such, our analysis focuses only on those plants most likely to be sued: the Phase I plants. This eliminates differences in regulatory regimes over the time period studied. ${ }^{4}$ Second, we delve into the EPA's decisions to target a certain set of plants in the lawsuits. BW focus on how the greater scrutiny affected plant operations and expenditures ex post. Third, our probability-of-lawsuit model identifies which plants were more likely to be sued, allowing us to see whether those plants responded more readily to the threat of enforcement. For their part, BW use the prevalence of scrubbers to capture relevant variation among power plants. Since a successful lawsuit by the EPA would require a plant to install scrubbers, plants that already had scrubbers were less likely to suffer large economic losses as a result of the lawsuits, and hence less likely to change their behavior. 


\section{Regulatory Background}

\section{Early Regulation}

Because this paper centers on the determinants of EPA's lawsuits, and the responses of the utility industry to the agency's actions, it is worth presenting the regulatory background in some detail. The roots of New Source Review lie in the 1970 Clean Air Act Amendments, when Congress first established federal authority over emissions from stationary sources such as coal-fired power plants. Reasoning that controlling pollution from new sources would be much less expensive than retrofitting older ones - and expecting that continued demand growth would lead utilities to replace older units as they aged - Congress established a nationwide uniform performance standard of $1.2 \mathrm{lbs}$. of $\mathrm{SO}_{2} / \mathrm{mmBtus}$ of coal, applicable on all new coal-fired generating units (among other categories of sources). In 1977, Congress amended the Clean Air Act further, augmenting the emissions-based standard with an additional requirement that individual sources reduce between 70 and 90 percent of the $\mathrm{SO}_{2}$ in their flue gas. The only way to meet this percentage reduction requirement was to install a "flue-gas desulfurization" device, better known as a "scrubber." Hence the 1977 Amendments effectively represent a technology standard. At the same time, the 1977 legislation strengthened the national ambient air quality standards.

To implement these regulations, EPA required all potential new sources of emissions to apply for a so-called "Permit to Construct," which triggered an extensive review of the proposed facility. The requirements for being granted such a permit were more stringent in "nonattainment areas" that did not meet the ambient air quality standards. Nonetheless,

costly pollution control requirements were still imposed on proposed sources in attainment areas, in order to prevent further deterioration of air quality. These stringent requirements on new sources created strong incentives for electric utilities to keep their older power plants in operation. Generating units built in the 1940s remained online years past their originally scheduled retirement dates, drawing the outrage of environmental advocacy groups and eventually attracting attention from regulators at EPA. 
Of course, Congress had anticipated this problem in the original legislation. The statutory definition of "new source" explicitly included sources that subsequently underwent "modification," defined as "any physical change in, or change in the method of operation of, a stationary source which increases the amount of any air pollutant emitted by such source ...." ${ }^{5}$ Taken literally, this provision would trigger New Source Review in response to virtually any maintenance operation at a power plant. Thus in implementing the Act, the EPA specified a more lenient characterization of "modification," which specifically required that the contemplated physical change result in a "significant net emissions increase" of pollution. In particular, EPA ruled out "routine maintenance, repair, and replacement" as a trigger for NSR. ${ }^{6}$ The scope of NSR was narrowed further in 1992, when EPA issued the so-called "WEPCo Rule" following a successful suit against the agency brought by the Wisconsin Electric Power Company. ${ }^{7}$ In July 1996, EPA announced a new effort to reform the NSR program, but couched it as "significantly reduc[ing] the number and types of activities at sources that would otherwise be subject to major NSR," "streamlin[ing] the overall NSR permitting process," and "relieving regulatory burden." ${ }^{8}$

\section{Threat of Enforcement}

In 1998, the EPA followed up with a second notice, ostensibly to solicit more detailed comments on the WEPCo rule proposal. In the announcement, however EPA signaled a shift to a much more vigorous stance in its enforcement of NSR in the electric power sector. Specifically, the agency declared that "it appears that although there are a number of substantial changes to existing units, as well as an increase in the amount of electricity being generated ... changes to utility units .... are not being reported to permitting agencies." The agency further warned that it had "reconsidered" the WEPCo rule's demand growth exclusion, and had "tentatively concluded that [it] should not be continued, ... especially in view of recent developments in the electric power sector." 9

These changes did not go unnoticed by the industry. In August, the Utility Environment Report ran an article headlined 'EPA Proposes 'WEPCo' Rule Changes; Would Required 
New Emissions Limits." In October, the industry's concerns increased, as word began to spread of imminent enforcement action against the electric utility industry. In an article entitled "EPA Seeking Naughty Coal-Fired Boiler Users," the Electricity Daily reported that agency had sent letters to several boiler manufacturers requesting information on "all coal-fired units over 25 MW constructed since 1930, subsequent recommended changes in operation, and any other known changes in operation since 1978." 10

NSR Lawsuits

A year later, on November 3, 1999, the Department of Justice, on behalf of the EPA, announced lawsuits against seven electric utilities (alleging violations at 24 power plants) as well as an administrative compliance order against the Tennessee Valley Authority (naming seven more plants). Subsequent lawsuits in March, April, and December of 2000 brought to 46 the total number of power plants targeted by the enforcement action. Table I lists the holding companies, utilities, and power plants named in the lawsuits.

The basis for EPA's legal action was its claim that utilities had made significant modifications to their power plants without notifying the agency. New Source Review does not prohibit the modification of plants: rather, it requires that firms inform the EPA of such changes and, if the changes are significant enough, that they meet the applicable New Source Performance Standards (NSPS). Hence while they did not point to explicit changes in emissions, all of the lawsuits cited specific modifications that (according to the EPA) should have been reported (Parker and Blodgett 2000). The stakes were considerable. A firm that lost a lawsuit could be required to meet the new source standard - installing scrubbers to capture $\mathrm{SO}_{2}$ and Selective Catalytic Reduction to control nitrogen oxides, at a cost of tens or hundreds of millions of dollars -or else shut down its plant. Firms also faced fines of up to $\$ 25,000$ per day of violation (Parker and Blodget 2000). To date, some of these lawsuits have been settled out of court (e.g., Cinergy agreed to pay $\$ 1.4$ billion to install pollution control technology, along with $\$ 8.5$ million in fines), while many are still pending. ${ }^{11}$

Our econometric analysis proceeds in three steps. First, we model the EPA's decision of 
which power plants to sue, using historical data on the likely determinants of the agency's enforcement action. Second, we look for evidence that the power plants that were eventually targeted - or those that were likely to be targeted - reduced their emissions in reaction to the threat of being sued. Finally, we ask whether such a response was rational: That is, did power plants that changed their behavior on the eve of the EPA's action affect the probability of a lawsuit?

\section{Model of Regulatory Enforcement Decision}

\subsection{Empirical Model of Enforcement}

We begin by modeling the probability that a given plant was named in the EPA's lawsuits in 1999 and 2000. For this analysis, we construct a cross-sectional sample of 249 coal-fired power plants that had at least one generating unit built before 1971 and therefore grandfathered out of the NSPS in the 1970 and 1977 Clean Air Acts. Therefore, each plant in our sample was potentially subject to New Source Review. These include all of the coal-fired "Table A" plants - plants that housed at least one unit required to participate in Phase I of the Title IV allowance market, named after the table in the 1990 Clean Air Act that listed them. ${ }^{12}$ The sample includes all 44 of the 46 plants named in the EPA lawsuits that were charged with evading new source review in the modification of existing emissions units. ${ }^{13}$

Section 6 asks whether utilities could avert regulatory enforcement. There, we will examine the link between contemporaneous behavior and the lawsuits. To begin with, however, we wish to model the probability that a plant was targeted in a lawsuit as a function of various fixed plant characteristics, along with past actions that had taken place well before the agency announced its plans to increase scrutiny of utilities. Such a model yields an "expected probability of being sued," based on factors that were purely exogenous by the time the electric utilities might have contemplated taking actions to avoid further scrutiny. In essence, this is a rational expectations model of the electric utilities' behavior. Given what 
had already occurred by the time the EPA altered its approach to New Source Review, how likely was a given plant to be targeted by the EPA for enforcement action?

The lawsuits filed by the EPA cited specific violations of the law that dated as far back to 1979 and were concentrated in the late 1980s and early- to mid-1990s. We start by focusing on behavior over the same period. In particular, all of the variables discussed in this section are computed using data for power plant operation from 1985 through 1997.

First, the EPA's definition of "major modification" sufficient to trigger New Source Review focused on changes that would increase a plant's emissions in expectation. Thus we would expect the lawsuits to have been more likely at plants that had large increases in emissions. We measure this in two ways: the maximum year-on-year change in emissions

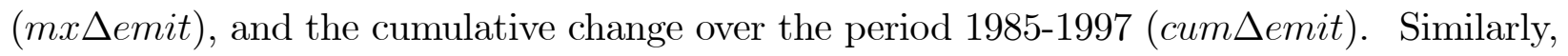
we include the maximum year-on-year and cumulative changes in generation $(m x \Delta g e n$ and cum $\Delta$ gen).

Next, the incentives to keep older plants operating were at the heart of the NSR controversy. Hence plants that reported large capital investments - either in a single year (mxinvest) or accumulated over time (mninvest) - might have attracted more attention from the EPA. High maximum or average maintenance expenditures (mxmaint and mnmaint, respectively) might have signaled an attempt to keep older plants operating past their normal lifetimes - or might have represented capital investment reported as maintenance to avoid scrutiny. Investment and maintenance figures are normalized by the generating capacity of a plant. Older plants (age) may also have been more likely to be sued.

Because the agency's objective was ultimately to limit the damages from deteriorating air quality, it might have taken account of the attainment status of the county in which a plant was located (attainment) or the environmental damages that a particular plant caused per ton of pollution (damages). Finally, to the extent that EPA chose high-profile cases to maximize the deterrent effect of its actions, it might have been more likely to identify violations at large power plants (plantsize), or at those plants owned by large parent utilities 
(firmsize). We take natural logarithms of age and firm size to account for the scaling of those variables. ${ }^{14}$

Under the assumption that idiosyncratic shocks $(\varepsilon)$ were drawn from a standard normal distribution, we estimate the probability of a lawsuit naming plant $i$ using the following probit model:

$$
\begin{aligned}
& \operatorname{Pr}\left(\text { lawsuit }_{i}\right)=X_{i}^{\prime} \beta_{i}+\varepsilon_{i} \text {, where } \\
& X_{i}^{\prime} \beta_{i}=\beta_{0}+\beta_{1} m x \Delta e m i t_{i}+\beta_{2}{\text { cum } \Delta e m i t_{i}}+\beta_{3} m x \Delta \text { gen }_{i}+\beta_{4} c u m \Delta \text { gen }_{i}+ \\
& \beta_{5} \text { mxinvest }_{i}+\beta_{6} \text { mninvest }_{i}+\beta_{7} \text { mxmaint }_{i}+\beta_{8} \text { mnmaint }_{i}+ \\
& \beta_{9} \ln \left(\text { age }_{i}\right)+\beta_{10} \text { attainment }_{i}+\beta_{11} \text { damages }_{i}+ \\
& \beta_{12} \ln \left(\text { plantsize }_{i}\right)+\beta_{13} \ln \left(\text { firmsize }_{i}\right) .
\end{aligned}
$$

We use the coefficient estimates from equation (1) to predict the likelihood that a given plant will be sued (probsue).

\subsection{Data for Enforcement Model}

The data in this study are taken from a range of publicly available government sources. We constructed the list of power plants sued by the EPA from press releases and reports published by the Department of Justice and the EPA, and made available on their websites.

The historical data used to calculate data on emissions and generation are from the Energy Information Administration (EIA) Form 767. For the years 1985 to 1997, annual emissions (in thousands of tons of $\mathrm{SO}_{2}$ ) were estimated on a mass-balance basis and used to compute the variables $m x \Delta e m i t$ and cum $\Delta$ emit. Generation figures for calculating $m x \Delta g e n$ and cum $\Delta$ gen were also computed from the EIA data.

The financial data are taken primarily from the Federal Energy Regulatory Commission (FERC) Form 1 and span the period 1981 to 1997. We construct our measure of capital investment by first computing total annual expenditures on structures and improvements, 
equipment, and land (reported in cumulative form on FERC Form 1), and then subtracting plant-level expenditures on abatement equipment (reported on EIA Form 767). Hence we do not count expenditures on scrubbers or other pollution control equipment, instead isolating the operational investments that are likely to invite regulatory scrutiny. The maxinvest and meaninvest variables are the maximum and mean of these annual "net dirty" investments, respectively; both are expressed in dollars per megawatt of nameplate generating capacity $(\$ / M W)$, expressing dollar amounts in real year-2000 terms using the appropriate HandyWhitman Electric Light and Power Construction cost index (taken from the 2003 Mergent Public Utility Manual). The FERC data also include annual maintenance expenses, used to compute mxmaint and mnmaint. These measures are also expressed in dollars per MW, using the producer price index for intermediate materials, goods, and components to convert dollar amounts into real (year-2000) terms.

We use the EPA's eGRID database for 1999 to construct the measures of age (in years as of 1999), and plantsize and firmsize (in gigawatts, GW or 1000 MW, of capacity). The indicator variable on $\mathrm{SO}_{2}$ county attainment status (attainment) is for the year 1990 . Environmental damages (damages) are based on a county-to-county source-receptor matrix for particulate matter (PM10), used by EPA to assess the benefits of clean air regulation (see Latimer (1996) and Abt (2000)). The receptor matrix specifies a transfer coefficient representing the effect of a ton of $\mathrm{SO}_{2}$ emissions from that source on ambient PM10 concentrations in each receptor county (in $\mu \mathrm{g} / \mathrm{m}^{3}$ ). We multiply each power plant's transfer coefficient by the 1990 population of the receptor county, and then sum over all 3080 receptor counties, to get our measure of per-ton damages for that plant. Thus the variable represents a population-weighted measure of the effect of one ton of $\mathrm{SO}_{2}$ emissions on ambient pollution concentrations. Table II presents summary statistics for the variables used in our analysis. 


\subsection{Results of Enforcement Model}

Table III presents the results of estimating the likelihood of being sued. Column 1 estimates the probability of a lawsuit as a function of historic behavior only, equation (1). Overall, the independent variables are reasonable predictors of the lawsuits $\left(\right.$ pseudo- $\left.R^{2}=0.40\right) .{ }^{15}$ The probability of a lawsuit increases with both maximum year-to-year changes in emissions and the cumulative increase in emissions from 1985-1997. Note that changes in generation did not affect the likelihood of a lawsuit. This suggests that to the extent EPA focused on plants that boosted their output, it did so as a means of targeting plants that increased emissions, rather than as an end in itself. The marginal effects of maximum and cumulative emissions, respectively, are 0.009 and $0.0009 .{ }^{16}$ Those estimates imply that the probability of a lawsuit rose by 1 percentage point for every 1100-ton increase in a plant's maximum year-on-year emissions, and by every 11,000-ton increase in cumulative emissions over the period.

Both mean investment and age also significantly increase the probability that a plant was targeted, suggesting that the EPA was indeed concerned about expenditures extending the operating lives of older power plants. An increase in mean annual investment of $\$ 2.54$ per MW of capacity (roughly 20 percent of the sample mean) raised the probability of a lawsuit by 1 percentage point. The estimated effect of age is more dramatic: the probability of a lawsuit rose by 1 percentage point with each 6 percent increase in age. ${ }^{17}$

Power plants owned by larger parent firms were more likely to be targeted by the agency, all else equal. A 15 percent increase in a firm's nameplate capacity, $3.1 \mathrm{GW}$ on average, corresponded to a 1 percentage point increase in the likelihood of a lawsuit. Large plants have similar marginal effects. These results are consistent with the EPA choosing high-profile cases in order to maximize the deterrent effect of its actions. On the other hand, measures of the environmental impacts of emissions (county attainment status and marginal damages) were not significant determinants of enforcement. 


\section{Firms' Response to Enforcement}

\subsection{Empirical Model of Firms' Response}

Next, we examine whether firms changed their emissions as a result of the lawsuits. For this analysis, we construct a panel data set that includes monthly observations for all coalfired Table A plants from 1996 to 2000. These plants faced a constant regulatory regime throughout the period. We exclude from the sample other older plants which were not required to participate in Phase I of the allowance market. ${ }^{18}$ Since those plants entered the allowance market in 2000, they confronted a new system of regulation precisely when the EPA began to crack down on NSR, which would complicate identification of the latter effect.

Recall that we are interested in measuring how plants responded to both the threat of enforcement action, and to the actual lawsuits. In our regressions, the dependent variable is the natural logarithm of tons of $\mathrm{SO}_{2}$ emitted at plant $i$ in month $t$ (emit $t_{i t}$ ). The first explanatory variable of interest is the threat of a lawsuit during the months leading up to the EPA's announcements. As our measure of the magnitude of that threat, we use the predicted probability from the probit regression in equation (1) $\left(\right.$ probsue $\left._{i}\right)$. We interact this with a dummy variable (threat ${ }_{i t}$ ) that equals one for plant $i$ starting in October 1998 and ending in either (i) the month before plant $i$ was named in a lawsuit, or (ii) December 2000. The result is our variable of interest, denoted $\operatorname{probsue}_{i} \cdot$ threat $_{i t}$, that equals the predicted probability of a lawsuit during the "threat window" running from October 1998 until a plant was sued (or through the end of the period under study). ${ }^{19}$ Since probsue $i$ is a generated regressor, we correct the estimated standard errors using the Murphy and Topel (1985) method.

The second key explanatory variable concerns the lawsuit itself. To measure the effect of enforcement actions after they were announced, we compute the variable lawsuit $_{i}$ - a dummy variable that equals one if plant $i$ was targeted by the EPA during 1999 and 2000. We interact this variable with an indictor of all months $t$ starting in the month that the enforcement 
action was announced and continuing to December 2000 (action $)_{t}$. The variable of interest is lawsuit $_{i} \cdot$ action $_{t}$. Of course, whether a power plant was named in the EPA's lawsuits may have depended in part on the plant's contemporaneous emissions (a possibility we examine directly in the next section). To address the simultaneity issue that arises when estimating how power plants responded to the enforcement action, we instrument for lawsuit $_{i} \cdot$ action $_{t}$ using the predicted probability from equation (1) in the months following an enforcement action (and zero beforehand): probsue $_{i} \cdot$ action $_{t}$.

The $\mathrm{SO}_{2}$ emitted from a power plant is the product of two quantities: the sulfur dioxide emissions rate (measured per mmBtus of fuel input), and the amount of fuel consumed. While the first of these can be altered at short notice (e.g., by using a fuel with a lower sulfur content), fuel consumption depends, in a large part, on how much electricity the plant generates, which is only partially under the control of the power plant's operator. We account for this by including monthly electricity generation $\left(\right.$ gen $\left._{i t}\right)$ in our regression. Since a power plant operator has some control over generation, we instrument for it using aggregate monthly state electricity demand $\left(\right.$ sales $\left._{i t}\right)$ heating degree-days $\left(h d d_{i t}\right)$, and cooling degree-days $\left(c d d_{i t}\right) .{ }^{20}$ We include plant-level fixed effects $\left(\delta_{i}\right)$ in the regression to control for unobserved characteristics of power plants. Finally, we include month-year fixed effects $\left(\zeta_{t}\right)$ to account for any determinants of emissions levels, common to all plants, that varied over time. (The most obvious example is the price of sulfur dioxide emissions under the emissions trading program.) The resulting model is:

$$
\ln \left(\text { emit }_{i t}\right)=\gamma_{1}\left(\text { probsue }_{i} \cdot \text { threat }_{i t}\right)+\gamma_{2}\left(\text { lawsuit }_{i} \cdot \text { action }_{t}\right)+\gamma_{3} \ln \left(\text { gen }_{i t}\right)+\delta_{i}+\zeta_{t}+v_{i t},
$$

using probsue $_{i} \cdot$ action $_{t}, \ln \left(\right.$ sales $\left._{i t}\right), \ln \left(h d d_{i t}\right)$, and $\ln \left(c d d_{i t}\right)$ to instrument for lawsuit $_{i} \cdot$ action $_{t}$ and $\ln \left(g e n_{i t}\right)$. 


\subsection{Data for Firms' Response}

In this section, we use data from the EPA's Continuous Emissions Monitoring System (CEMS). The EPA collects hourly data on $\mathrm{SO}_{2}$ emissions and gross generation for most fossil-fueled generating units in the US. ${ }^{21}$ CEMS data are highly accurate and comprehensive for most types of fossil units (Joskow and Kahn, 2002). We aggregate these data by plant and month.

The data used to construct the instruments are from two sources. Electric utilities report hourly demand (FERC Form 714) that we aggregate by month and state. We compute the monthly statewide heating and cooling degree-days from National Oceanic and Atmospheric Administration (NOAA) data. ${ }^{22}$

\subsection{Results of Firms' Response}

Table IV presents results from regressions of emissions on measures of enforcement (equation (2)), using panel data for 1996-2000. All of the regressions reported in the table instrument for lawsuit ${ }_{i} \cdot$ action $_{t}$ and include plant and month-year fixed effects. We compute NeweyWest standard errors allowing for a six-month lag structure, to account for the possibility of (unspecified) autocorrelation among observations from the same plant. Column 1 presents estimates without instrumenting for generation; to the extent utilities shifted output away from plants that were at high risk of being targeted, these estimates will be biased. Column 2 presents our main specification - instrumenting for $\ln \left(\right.$ gen $\left._{i t}\right)$ and lawsuit $_{i} \cdot$ action $_{t}$ with sales, heating/cooling degree-days, and the predicted probability of a suit (using the $\widehat{\beta}$ coefficients in Table III). The instruments are strong. ${ }^{23}$ Over-identification tests fail to reject the null hypothesis that the instruments are valid. ${ }^{24}$ As a robustness check on our instrumenting strategy, column 3 of Table IV presents estimates using an alternative set of instruments: namely, the full set of covariates in equation (1), as well as $\ln \left(\right.$ sales $\left._{i t}\right), \ln \left(h d d_{i t}\right)$, and $\ln \left(c d d_{i t}\right) .{ }^{25}$

Because we include plant fixed effects and measure emissions in logs, the coefficient on 
probsue $_{i} \cdot$ threat $_{i t}, \gamma_{1}$, estimates the percent change in emissions during the "threat window" relative to prior emissions at the same plant, controlling for contemporaneous generation. This is negative and statistically significant at the 1-percent level in all three specifications presented in Table IV. Hence plants with a greater probability of being sued reduced their emissions by a larger percentage. Using the estimated coefficients in the main specification of column 3, a plant that faced nearly certain enforcement (i.e., probsue near one) reduced emissions by approximately 33 percent. ${ }^{26}$ Of course, the incentive to avert enforcement was most relevant for plants on the margin. Looking across plants, a one standard deviation increase in the probability of being sued (about 0.28) results in a ten percent reduction in emissions. The interquartile difference was roughly the same magnitude; hence moving a plant from the 25 th percentile of probsue to the $75^{\text {th }}$ percentile also corresponded to a roughly ten percent increase in emissions. At the median plant, this corresponds to a drop in annual emissions of 280 tons of $\mathrm{SO}_{2}$ relative to 1996-1998 levels. By comparison, the drop in emissions during the first year of the $\mathrm{SO}_{2}$ emissions trading program under the 1990 Clean Air Act (one of the most ambitious pollution control policies in the country's history) was on the order of one-third. ${ }^{27}$

These findings correspond to the emissions response to the threat of the lawsuits, regardless of whether a plant was actually sued or not. The effect of the lawsuits themselves is captured by the coefficient on lawsuit $_{i} \cdot$ action $_{t}, \gamma_{2}$. The estimates in Table IV suggest that a power plant's emissions fell by about 18 percent after the announcement of an EPA lawsuit, relative to emissions prior to October 1998. This is half the magnitude of the estimated coefficient on the probsue $_{i} \cdot$ threat $_{i t}$ variable. One possible explanation for the dampened response after firms were named in the lawsuits, compared to the threat, is the firms had already optimally adjusted.

Of course, there is a key difference in the range of the independent variables. The severity of the threat differed across plants, with a median of only 0.07 . Hence while plants at greater risk responded sharply to the threat of lawsuits, the "average plant" reduced 
emissions by only a few percentage points. In contrast, a power plant was either sued - in which case it reduced emissions by 18 percent on average or it was not. Taken together, the evidence suggests that firms responded to the threat of the lawsuits, as well as to the lawsuits themselves.

\subsection{Robustness Tests}

Our identification strategy is simple: it rests on comparing emissions during the threat window to prior emissions. One way to check the robustness of our results is to run a "false experiment," using an alternative (arbitrary) event window in place of the actual one to define the probsue $_{i} \cdot$ threat $_{i t}$ variable. Table V presents the results of defining the threat as equal to probsue $_{i}$ during the years 1997 or 1998 only (the specification is otherwise the same as in column 2 of Table IV). ${ }^{28}$ The estimates fail to find any significant effect, consistent with our premise that the EPA's announcements in 1998 presaged a shift in the enforcement regime.

We then examine how firms reduced emissions. The EIA Form 767 data provide information on the sulfur content of a plant's coal each month. Replacing the dependent variable in equation (2) with the natural logarithm of sulfur content, we find that those plants more likely to be named in lawsuits switched to lower sulfur coal (the coefficient on probsue $_{i} \cdot$ threat $_{i t}$ is -0.139 (s.e. of 0.044$)$ ). However, there was no significant response to the lawsuits themselves $\left(\right.$ lawsuit $_{i} \cdot$ action $\left._{t}\right)$ : -0.009 with a s.e. of 0.051 . We find similar results if we use the natural logarithm of the emissions rate (in lbs. of $\mathrm{SO}_{2} / \mathrm{mmBtus}$ ) as the dependent variable. ${ }^{29}$ Given the magnitudes of these findings and those reported in Table IV, we posit that firms reduced emissions by reducing both emissions rates (primarily through fuel switching) as well as output. 


\section{Regulatory Response to Changing Emissions}

\subsection{Empirical Model of Regulatory Response}

Finally, we return to the question of which plants were named in the EPA's lawsuits. This time, however, we are interested in whether there was any "rational" basis for power plant operators to change their behavior in the months leading up to the lawsuits. To investigate this question, we introduce the change in the natural logarithm of emissions from the 12 month period before the announcement, October 1997 to September 1998, to the 12-month period afterwards, October 1998 to September 1999, $\left(\Delta \ln \left(e m i t_{i}\right)\right)$ as an explanatory variable in our "likelihood of lawsuits" model (equation (1)).

As noted above, lawsuits and contemporaneous emissions may have been jointly determined. Thus we instrument for the change in emissions using the change over the same time period in the natural logarithm of state electricity demand. ${ }^{30}$ The model is now:

$$
\operatorname{Pr}\left(\text { lawsuit }_{i}\right)=\alpha\left(\Delta \ln \left(\text { emit }_{i}\right)\right)+X_{i}^{\prime} \beta_{i}+\varepsilon_{i},
$$

using the change in the natural logarithm of sales $\left(\Delta \ln \left(\right.\right.$ sales $\left.\left._{i}\right)\right)$ as an instrument for $\Delta \ln \left(\right.$ emit $\left._{i}\right)$ (compare with equation (1)). We estimate equation (3) on the cross section of power plants described in section $4 .{ }^{31}$

\subsection{Data for Regulatory Response}

This section combines those plant characteristic data from section 4.2 with the monthly data on emissions and sales from section 5.2. The variable of interest, $\Delta \ln \left(e m i t_{i}\right)$, is defined using emissions data from October 1997 to September 1999 using the CEMS data. For the 249 plants in the sample, the average change in emissions was -245 tons or approximately 8 percent. 


\subsection{Results of Regulatory Response}

Our motivating premise is that firms sought to avert being sued by reducing their emissions on the eve of enforcement. If so, we should find evidence that current emissions positively affected the probability of a lawsuit. To explore this possibility, we re-estimate the probability of a lawsuit using equation (3), this time including the change in plant-level emissions.

Of course, estimating the effect of contemporaneous behavior on the EPA's decision raises econometric concerns. After all, we have just shown that power plants reduced their emissions in anticipation of the lawsuits. Hence a power plant at greater risk of being sued (for unrelated reasons) was likely to reduce its emissions on the eve of the lawsuits, in the hopes of mollifying the agency. Such behavior would generate a negative correlation between changes in emissions and the probability of being sued - obscuring the evidence of its effectiveness (i.e., whether in the absence of a plant's response it would have been more likely to be sued). This is a standard simultaneity problem; if we include the change in emissions as an explanatory variable in estimating the probability of a lawsuit, we would expect biased results. ${ }^{32}$

To underscore this point, column 1 of Table VI presents estimates from standard maximum likelihood estimation of equation (3), without instrumental variables. The results are little different from the estimates of equation (1) presented in Table III. ${ }^{33}$ In particular, the estimated coefficient on $\Delta \ln \left(\right.$ emit $\left._{i}\right)$ is essentially zero. This null result begs the question: Was the EPA's decision determined entirely by the actions of power plants before 1998? Or are the averting effects of eleventh-hour changes in emissions being canceled out by the fact that the plants undertaking such measures were more likely to be sued to begin with?

We untangle these effects by instrumenting for the change in emissions with changes in the natural logarithm of state sales. Results for the first stage are presented column 2 of Table VI. The instrument is statistically significant at the 5-percent level. In addition, the model predicts that plants with lower maximum historical changes in emissions and those in attainment areas had increased emissions relative to others. 
Column 3 of the table presents estimates from the second stage of the instrumentalvariables model (equation (3)). The results confirm the relevance of contemporaneous behavior to the enforcement decision, and reveal the averting effect that was obscured in column 1. Controlling for a range of other determinates of a lawsuit (all of which were fixed before 1998), power plants with larger increases in emissions at the time of the treat of enforcement were much more likely to be targeted by the EPA. Even with current emissions included in the analysis, the maximum historic increase in emissions ( $m x \Delta e m i t)$ remains a strong predictor of a lawsuit. However, investment, age, plant size, and firm size lose their predictive power. Interestingly, in this model, plants in nonattainment areas were also more likely to be sued. (In Table III, the coefficient is similar in magnitude but has a large standard error.)

The key conclusion to emerge from Table VI is that the lawsuits were responsive to the emissions decisions of the firms. This buttresses our analysis of the response by power plants. Since even eleventh-hour reductions in emissions helped stave off enforcement action by the EPA, firms did indeed have reason to respond strategically to the threat of enforcement.

\subsection{Robustness Test using Three-Stage Least Squares}

In estimating equation (2), we have used as our measure of the threat of enforcement the predicted probability of being sued based on equation (1). To avoid endogeneity concerns, we estimated the likelihood of a lawsuit on the basis of factors that were exogenous by the time the EPA announced its shift in approach. Nonetheless, the underlying logic of our model might also suggest that the lawsuits and the utilities' actions in anticipation of the lawsuits were jointly determined. To account for this possibility, we next estimate equations (2) and (3) as a system, using three-stage least squares (3SLS).

While appealing in principle, this approach raises a few complications that must be addressed in practice. First, our sample size for the likelihood-of-lawsuit model falls to 102 plants (from 249). This is because only Table A units faced the same environmental regulation (namely Phase I of the 1990 Clean Air Act Amendments' Title IV program) 
during the entire time period studied. ${ }^{34}$ Second, the 3SLS model requires assuming a linear probability model, rather than the probit used above.

Third, and arguably most importantly, the equations do not neatly fit into the 3SLS framework. Typically, a 3SLS model is of the form:

$$
\begin{aligned}
& y_{i, 1}=X_{i} \beta_{1}+\alpha_{1} y_{i, 2}+Z_{i, 1} \gamma_{1}+\varepsilon_{i, 1} \\
& y_{i, 2}=X_{i} \beta_{2}+\alpha_{2} y_{i, 1}+Z_{i, 2} \gamma_{2}+\varepsilon_{i, 2}
\end{aligned}
$$

Our case, however, raises several difficulties. Equation (1), the likelihood of being sued, is a cross section, while equation (2), emissions, is a panel. Furthermore, the equations are not simple linear functions of each other. While emissions (say, $y_{2}$ in the above system of equations) do affect the probability of being sued, it is the change in emissions around the time of the threat (October 1997 to September 1999) that matters, rather than the level. Similarly, we are interested in the response of emissions not only to the actuality of a lawsuit after the EPA's action $\left(y_{1}\right)$, but also to the likelihood of being sued $\left(E\left(\left[y_{1}\right]\right)\right)$, during the "threat window" leading up to the EPA's actions. Thus, the correct system of equations would replace $y_{i t, 2}$ and $y_{i t, 1}$ with $f\left(y_{i t, 2}\right)$ and $g\left(y_{i t, 1}\right)$, respectively, in equations (4) and (5) above.

Nonetheless, despite its shortcomings, the 3SLS model provides a useful means of probing the robustness of our main approach. In place of equation (3), we estimate a linear probability model, using the same (exogenous) regressors as in the earlier specification, along with the change in emissions during the threat window $\left(\Delta \ln \left(e^{2} i_{i}\right)\right)$. In the spirit of equation (2), we estimate $\Delta \ln \left(\right.$ emit $\left._{i}\right)$ as a function of whether the plant was named in a lawsuit (lawsuit ${ }_{i}$ ) and its change in electricity generation, $\Delta \ln \left(g e n_{i}\right)$. Furthermore, like the instruments in equation (2), the change in generation is a function of the change in sales, $\Delta \ln ($ sales $)$, heating degree-days, $\Delta \ln (h d d)$, and cooling degree-days, $\Delta \ln (c d d)$.

In Table VII, we present results of simultaneous estimation of the three equations. A 
plant's likelihood of being named in a lawsuit increases with changes in current emissions, changes in historic emissions, and firm size. Changes in emissions are increasing in generation and are smaller if the plant was named in a lawsuit. With this small sample, the weather and demand variables are weak predictors of generation. Overall, we conclude that the results are comparable to those highlighted above in Tables III, IV, and VI.

\section{Conclusions}

In this paper, we have explored how electric utilities responded to greater regulatory scrutiny and an increased threat of enforcement. In line with the public stance taken by the EPA, we find that the probability of enforcement action was higher at plants with large, historic emissions increases or capital investments. However, the agency was also more likely to target large plants and plants owned by large utilities.

We then estimate the strategic responses of firms to the threat of enforcement, using our model of the lawsuit decision to construct predicted enforcement probabilities. This provides a measure of how vulnerable each plant was to the increased regulatory threat. We find that plants that were more likely to be sued (based on decisions stretching back over the prior two decades) reduced their emissions by more, even controlling for fixed plant and monthyear effects. On the eve of the lawsuits, emissions at plants with a one standard deviation greater probability of being sued fell approximately ten percent. We conclude that firms sought to avert enforcement. In addition, the plants named in lawsuits reduced emissions by approximately 18 percent.

Finally, we examine whether the government did respond to the reduced emissions. When

we include a plant's contemporaneous emissions in the lawsuit model, we find that it is a strong predictor of whether the plant was sued. We take this as evidence that firms had reasonable grounds to change their behavior in order to avert enforcement.

Taken together, these results suggest a complementary pair of conclusions. Firms appear 
to respond strategically to a perceived threat of enforcement, changing their behavior to avert the scrutiny of regulators. Furthermore, these actions are effective: regulators $d o$ take these actions into account when determining whether or not to enforce regulation on firms. 


\section{References}

[1] Abt Associates, 2000, "The Particulate-Related Health Benefits of Reducing Power Plant Emissions," prepared for Clean Air Task Force (October).

[2] Anton, W., G. Deltas, and M. Khanna, 2004, "Incentives for Environmental SelfRegulation and Implications for Environmental Performance," Journal of Environmental Economics and Management, 48, 632-654.

[3] Bartel, A. and L. Thomas, 1985, "Direct and Indirect Effects of Regulations: A New Look at OSHA's Impact," Journal of Law and Economics, 28, 1-25.

[4] Bushnell, J. and C. Wolfram, 2006, "The Economic Effects of Vintage Differentiated Regulations: The Case of New Source Review," CSEM Working Paper CSEM WP-15\%.

[5] Eckert, H., 2004, "Inspections, Warnings, and Compliance: The Case of Petroleum Storage Regulation," Journal of Environmental Economics and Management, 47, 232259.

[6] Fabrizio, K., N. Rose, and C. Wolfram, forthcoming, "Do Markets Reduce Costs? Assessing the Impact of Regulatory Restructuring on U.S. Electric Generation Efficiency," American Economic Review.

[7] Glachant, M., 2007, "Non-Binding Voluntary Agreements," Journal of Environmental Economics and Management, 54, 32-48.

[8] Gray, W. and M. Deily, 1996, "Compliance and Enforcement: Air Pollution Regulation in the U.S. Steel Industry," Journal of Environmental Economics and Management, 31, $96-111$.

[9] Joskow, P. and E. Kahn, 2002, "A Quantitative Analysis of Pricing Behavior In California's Wholesale Electricity Market During Summer 2000," Energy Journal, 23, 1-35. 
[10] Khanna, M. and W. Anton, "Corporate Environmental Management: Regulatory and Market-Based Incentives," Land Economics, 78, 539-558.

[11] Laplante, B. and P. Rilstone, 1996, "Environmental Inspections and Emissions of the Pulp and Paper Industry in Quebec," Journal of Environmental Economics and Management, 31, 19-36.

[12] Latimer, D., 1996, "Particulate Matter Source-Receptor Relationships Between All Point and Area Sources in the United States and PSD Class I Area Receptors," prepared for EPA Office of Air Quality Planning \& Standards, September.

[13] List, J., D. Millimet, and W. McHone, 2004, "The Unintended Disincentive in the Clean Air Act," Advances in Economic Analysis 83 Policy, 4, 26 pages.

[14] Lutz, S., T. Lyon, and J. Maxwell, 2000, "Quality Leadership When Regulatory Standards Are Forthcoming," Journal of Industrial Economics, 48, 331-348.

[15] Lyon, T. and J. Maxwell, 2003, "Self-Regulation, Taxation and Public Voluntary Environmental Agreements," Journal of Public Economics, 87, 1453-1486.

[16] Lyon, T. and J. Maxwell, 2004, Corporate Environmentalism and Public Policy, Cambridge, UK: Cambridge University Press.

[17] Magat, W. and W. Viscusi, 1990, "Effectiveness of the EPA's Regulatory Enforcement: The Case of Industrial Effluent Standards," Journal of Law and Economics, 33, 331-360.

[18] Maloney, M. and G. Brady, 1988, "Capital Turnover and Marketable Pollution Rights," Journal of Law and Economics, 31, 203-226.

[19] Maxwell, J., T. Lyon, and S. Hackett, 2000, "Self-Regulation and Social Welfare: The Political Economy of Corporate Environmentalism," Journal of Law and Economics, $43,583-617$. 
[20] Montero, J., 1999, "Voluntary Compliance with Market-Based Environmental Policy: Evidence from the U.S. Acid Rain Program," Journal of Political Economy, 107, 9981033.

[21] Murphy, K, and R. Topel, 1985, "Estimation and Inference in Two-Step Econometric Models," Journal of Business and Economic Statistics, 3, 88-97.

[22] Nelson, R., 1984, "Regulation, Capital Vintage and Technical Change in the Electric Utility Industry," Review of Economics and Statistics, 66, 59-69.

[23] Nelson, R., T. Tietenberg, and M. Donihue, 1993, "Differential Environmental Regulation: Effects on Electric Utility Capital Turnover and Emissions," Review of Economics and Statistics, 75, 368-373.

[24] Parker, L. and J. Blodgett, 2000, "Air Quality and Electricity: Enforcing New Source Review," CRS Report for Congress, available at: http://www.ncseonline.org/nle/crsreports/air/air-35.cfm.

[25] Stavins, R., 2006, "Vintage-Differentiated Environmental Regulation," Stanford Environmental Law Journal, 25, 29-63. 


\section{Notes}

${ }^{1}$ Lyon and Maxwell (2003) examine self-regulation in the context of "public voluntary agreements." The authors develop a model showing when such agreements may reduce welfare. Furthermore, in the case of minimum quality standards set by regulators, a firm of high quality can induce the regulator to weaken standards, thereby lowering welfare (Lutz et al. 2000). Voluntary agreements with polluters may also reduce welfare, depending on the strength of congressional lobbyists (Glachant 2007).

${ }^{2}$ The studies that have taken explicit account of endogeneity have also framed their analysis in terms of the threat of enforcement; see for example Laplante and Rilstone (1996). But the use of an instrumental variables strategy simply ensures that the effect of enforcement is identified by the exogenous component of enforcement. Examining the effect of the threat of action distinct from the actual action requires analyzing a window of time during which enforcement was imminent but had not yet taken place.

${ }^{3}$ See Stavins (2006) for an overview of the literature on VDRs.

${ }^{4}$ In contrast, BW consider a more diffuse sample of 329 plants subject to a variety of regulatory regimes. This provides them with a greater scope of exploring vintage differentiated regulations. However, Phase I and Phase II plants are likely to have very different responses circa 2000, the beginning of Phase II, and hence to the regulatory window.

${ }^{5} 72$ USC $\S 7411(\mathrm{a})$.

${ }^{6}$ See, for example, CFR $\S 51.166(\mathrm{~b})(2)$.

${ }^{7}$ The ruling in that case by the U.S. Court of Appeals (7th Circuit) established that power plants could carry out "like-kind replacements" of boiler components without triggering New Source Review, and led the EPA to revise its methodology for estimating and evaluating the increased emissions that would result from changes to existing units in the electric power sector. In particular, the new rule excluded emissions increases due to growth in electricity demand. Even so, considerable ambiguity remained.

${ }^{8}$ See the announcement of the proposed rule in the Federal Register, vol 61, No., 142 (July 
23, 1996), p38251. Among other proposals was a suggestion that the EPA might extend some of the WEPCo methodology to other industrial sectors.

${ }^{9}$ See the Federal Register, vol 63, No., 142 (July 24, 1998), p. 39860.

${ }^{10}$ The article went on to report that: "Agency officials believe an in-depth investigation will show that many utilities and other generators have not disclosed boiler modifications that would trigger new source review .... EPA reportedly plans to target 25 power plants initially for investigation and possible enforcement action." (Electricity Daily, vol. 11, No. 72, October 13, 1998)

${ }^{11}$ For more on NSR, see http://www.epa.gov/nsr/index.html. Unfortunately, our data do not allow use to examine how emissions have changed either at plants that have settled or at threatened plants since President Bush took office. (Only one case has been brought by the Bush administration.) We leave this to future research.

${ }^{12}$ Specifically, the analysis includes 105 of the 110 Table A plants. Five plants with Table A units are excluded: Breed (IN); Des Moines (IA), and North Oak Creek (WI), whose Table A units were retired by 1994; and Northport and Port Jefferson (NY), which did not burn coal. The remaining 144 plants in the data housed units on which construction began before 1971, hence were grandfathered out of the NSPS and subject to state regulation.

${ }^{13}$ The violations at the remaining two plants (the Miller and Scherer Plants operated by Georgia Power) concerned units that were built after the 1977 Amendments took effect but did not comply with the relevant NSPS. Hence their presence on the list of plants targeted by the EPA can easily be explained by their flagrant violation of the clear meaning of the legislation, rather than the nuances of how it was implemented by the agency.

${ }^{14}$ Our conclusions are unaffected by including these variables in other ways, e.g., letting age enter quadratically. We measure emissions, investment, and maintenance in levels because these variables take on negative values, reflecting declining emissions or utilization, or capital depreciation (i.e., negative net investment).

${ }^{15}$ In order to predict 90 percent of the plants named in lawsuits, we need to consider all 
plants with predicted probabilities of 0.14 or above to be sued. However, about 56 percent (49 of 88 plants) with predicted probabilities above this cutoff were not actually sued.

${ }^{16}$ We calculate the marginal effects for each observation and report the sample mean. This is done using the margeff command in Stata 9.0

${ }^{17}$ We test the robustness of the model specification to alternative functions of age. For example, we also include $\ln ($ age $) \cdot \ln ($ age $)$. However, the variable is insignificant $(-1.21$ with a standard error (s.e.) of 1.07) so is excluded from the main specification.

${ }^{18}$ Although some of these plants voluntarily participated in Phase I as "substitution units," the ones that chose to do so had already reduced their emissions for other reasons (Montero, 1998). Because of this adverse selection effect, we choose to focus on the plants that were required to participate in Phase I. Our results are unaffected by the inclusion of the nonTable A plants that participated in Phase I.

${ }^{19}$ We also test the functional form of this variable. One might expect that for plants very likely to be named in lawsuits, there is little point in attempting to appease regulators. We test this hypothesis by including a quadratic function of probsue $_{i} \cdot$ threat $_{i t}$. We find that the linear variable remains significant and negative (-0.52 with a s.e. of 0.15$)$. The squared term is positive as expected, 0.34, though the standard error is large (0.27).

${ }^{20}$ These variables are standard instruments for generation (for example, see Fabrizio, Rose, and Wolfram (forthcoming)). Retail electricity prices are fixed for long periods of time, making short run demand for electricity extremely inelastic and a valid instrument. Heating (cooling) degree days are the number of degrees the average daily temperature was below (above) $65^{\circ} \mathrm{F}$, which we aggregate over the month.

${ }^{21}$ All units over $25 \mathrm{MW}$ and new units under $25 \mathrm{MW}$ that use fuel with a sulfur content greater than 0.05 percent by weight are required to measure and report emissions under the Acid Rain Program. Gross generation differs from net generation because of the discrepancy between electricity generated by a unit and the amount of electricity sold onto the grid. This discrepancy arises from internal power usage for water pumps, conveyor belts, etc. Informal 
data on gross to net ratios suggest an average ratio of 1.05 to 1.1. More importantly for this analysis, the ratios remain relatively constant for a given plant.

${ }^{22}$ NOAA reports the daily mean temperature at hundreds of weather stations nationwide. We calculate statewide daily averages of these weather stations and compute $h d d$ and $c d d$ as defined in footnote 20. See U.S. Department of Commerce, National Climatic Data Center, NOAA Satellite and Information Service [http://www7.ncdc.noaa.gov/IPS/getcoopstates.html]).

${ }^{23}$ For both first stages, Wald tests on the joint significance of the instruments are significant at the 1-percent level: $\ln \left(\right.$ gen $\left._{i t}\right)$ (F-stat of 19.2); and lawsuit $_{i} \cdot$ action $_{t}($ F-stat of 168).

${ }^{24}$ For example, for the Sargan $N * R^{2}$ test, the $\chi^{2}=0.13$ (p-value $=0.938$ ). We reach similar findings using the other tests of overidentification that are calculated by the overid command in Stata 9.0 .

${ }^{25}$ For this specification, the instruments are also strong, with Wald tests significant at the 1-percent level: lawsuit $_{i t}$ (F-stat of 3993); and gen $_{i t}$ (F-stat of 6.2). In this case, the Sargan over-identification test rejects the null hypothesis $\left(\chi^{2}=88, p-\right.$ value $\left.=0.001\right)$.

${ }^{26}$ Percent change is approximately $e^{\gamma_{1}}-1$.

${ }^{27}$ Using the data described in section 4.2, we calculate that Table A plants emitted 7,434,616 tons of $\mathrm{SO}_{2}$ in 1994 and 4,782,639 tons in 1995.

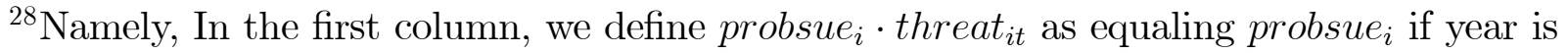
1997, zero else. In the second column, the variable equals probsue $i$ if year is 1998 (and zero otherwise).

${ }^{29}$ The coefficient on probsue $_{i} \cdot$ threat $_{i t}$ is -0.218 (s.e. of 0.046 ) and the coefficient on lawsuit $_{i} \cdot$ action $_{t}$ is -0.092 (s.e. of 0.053$)$.

${ }^{30}$ We initially used sales and heating/cooling degree-days as instruments for emissions, like in equation (2). However, the temperature variables were weak instruments (a Wald test rejects the joint significance of the weather variables: F-stat of 0.60 ).

${ }^{31}$ We use the ivprobit command in Stata 9.0.

${ }^{32}$ It may appear that including the change in emissions without instrumenting would 
capture the effect of the strategic response we are interested in. But note that we are interested in isolating the effect of contemporaneous behavior on the EPA's actions, rather than in whether plants that reduced emissions ended up more or less likely to be sued. This is akin to examining how prices change with quantities: without some clear identification strategy such as instrumental variables, it is not clear whether the variation is from supply or demand shocks. In our context, we want to understand the best response functions of both firms and of the government. In section 5, we estimated the firms' response function. Here, we are estimating the response function of the government.

${ }^{33} \mathrm{~A}$ Hausman test rejects that the coefficients of the variables common to both equations (1) and (3) are significantly different $\left(\chi^{2}=9.6\right)$.

${ }^{34}$ Of the 105 Table A plants in our panel, moreover, three lack generation data-bringing the sample size down to 102. If we estimate the model on the full sample, we get qualitatively similar results for the likelihood model (changes in current and historic emissions, age, and firm size increase the likelihood of a lawsuit), changes in cooling degree-days increase changes in generation, and changes in generation increase changes in emissions. However, in this sample, the lawsuit does not significantly affect changes in emissions. Given the sample includes many Phase II plants, these results should be treated with caution. 


\section{Table I: Companies and Power Plants Sued for Violating NSR}

\begin{tabular}{lll} 
Holding Company (Utility) & Date of Lawsuit & Power Plants \\
\hline American Electric Power (Cardinal) & November 1999 & Cardinal \\
AEP (Central Operating) & November 1999 & Philip Sporn \\
AEP (Indiana Michigan Power) & November 1999 & Tanners Creek \\
AEP (Ohio Power) & November 1999 & Mitchell; Muskingum River \\
Cinergy (Cincinnati Gas \& Electric) & November 1999 & Walter C Beckjord \\
Cinergy (Psi Energy) & November 1999 & Cayuga \\
Dynegy (Illinois Power) & November 1999 & Baldwin \\
FirstEnergy (Ohio Edison) & November 1999 & W H Sammis \\
Southern (Alabama Power) & November 1999 & Barry; Gorgas; James H Miller Jr \\
Southern (Georgia Power) & November 1999 & Bowen; Scherer \\
TECO Energy (Tampa Electric) & November 1999 & Big Bend; F J Gannon \\
Tennessee Valley Authority & November 1999 & T H Allen; Bull Run; Colbert; Cumberland; \\
& & John Sevier; Paradise; Widows Creek \\
Vectren (Southern Indiana Gas \& Elec) & November 1999 & F B Culley \\
AEP (American Electric Power) & March 2000 & Clinch River; John E Amos; Kanawha River \\
AEP (Columbus Southern Power) & March 2000 & Conesville \\
AEP (Ohio Power) & March 2000 & Kammer \\
Cinergy (Psi Energy) & March 2000 & R Gallagher; Wabash River \\
Southern (Alabama Power) & March 2000 & E C Gaston; Greene County \\
Southern (Gulf Power) & March 2000 & Crist \\
Southern (Mississippi Power) & March 2000 & Jack Watson \\
Southern (Savannah Electric \& Power) & March 2000 & Kraft \\
Tennessee Valley Authority & April 2000 & Kingston; Shawnee \\
Duke Energy Corporation & December 2000 & Belews Creek; Buck; Cliffside; Dan River; \\
\hline & & G G Allen; Marshall; Riverbend; W S Lee \\
\hline
\end{tabular}


Table II: Summary Statistics

\begin{tabular}{|c|c|c|c|c|c|}
\hline Variable & units & mean & s.d. & $\min$ & $\max$ \\
\hline lawsuit & $0 / 1$ & 0.18 & 0.38 & 0.00 & 1.00 \\
\hline$m x \Delta e m i t$ & 000 tons & 11.72 & 11.95 & 0.24 & 75.54 \\
\hline cum $\Delta$ emit & 000 tons & -16.12 & 48.23 & -320.26 & 73.20 \\
\hline$m x \Delta g e n$ & GWh & 992.39 & 924.17 & 48.20 & 6171.40 \\
\hline cum $\Delta$ gen & GWh & 537.46 & 1311.27 & -3649.72 & 7130.68 \\
\hline mxinvest & \$/MW & 96.05 & 123.23 & -0.17 & 587.01 \\
\hline mninvest & $\$ / M W$ & 12.58 & 15.99 & -53.75 & 92.13 \\
\hline mxmaint & \$/MW & 31.34 & 19.35 & 7.95 & 154.60 \\
\hline mnmaint & \$/MW & 20.08 & 10.31 & 3.50 & 59.02 \\
\hline age & years & 45.66 & 15.18 & 20.00 & 99.00 \\
\hline attainment & $0 / 1$ & 0.10 & 0.31 & 0.00 & 1.00 \\
\hline damages & see text & 2.89 & 2.01 & 0.00 & 10.95 \\
\hline plantsize & GW & 0.89 & 0.73 & 0.10 & 3.54 \\
\hline firmsize & GW & 21.26 & 19.00 & 0.32 & 66.56 \\
\hline
\end{tabular}

Notes: 249 observations 
Table III: Likelihood of Lawsuits

Dependent variable: Indicator of power plant named in lawsuit (0/1)

\begin{tabular}{|c|c|c|c|}
\hline Variable & Coefficient & Std. err & $\mathrm{dF} / \mathrm{dx}$ \\
\hline$m x \Delta e m i t$ & $0.0583 * * *$ & 0.0145 & 0.0090 \\
\hline cum $\Delta e m i t$ & $0.0058 * *$ & 0.0027 & 0.0009 \\
\hline$m x \Delta g e n$ & -0.0002 & 0.0002 & 0.0000 \\
\hline cum $\Delta g e n$ & 0.0001 & 0.0001 & 0.0000 \\
\hline mxinvest & 0.0008 & 0.0013 & 0.0001 \\
\hline mninvest & $0.0254^{*}$ & 0.0132 & 0.0039 \\
\hline mxmaint & -0.0288 & 0.0308 & -0.0045 \\
\hline mnmaint & -0.0279 & 0.0477 & -0.0043 \\
\hline $\ln ($ age $)$ & $1.0762 * *$ & 0.5349 & 0.1665 \\
\hline attainment & -0.5456 & 0.4901 & -0.0732 \\
\hline damages & -0.0756 & 0.0715 & -0.0117 \\
\hline $\ln ($ plantsize $)$ & $0.4865^{*}$ & 0.2683 & 0.0753 \\
\hline $\ln ($ firmsize $)$ & $0.4406 * * *$ & 0.1480 & 0.0682 \\
\hline constant & $-5.6097 * * *$ & 2.0153 & \\
\hline
\end{tabular}

Notes: 249 observations. We note significance at the 1-percent level (***), 5-percent level (**), and 10-percent level (*). Psuedo- $\mathrm{R}^{2}$ of 0.40 . 
Table IV: $\mathrm{SO}_{2}$ Emissions Response to Lawsuits

Dependent variable: $\ln ($ emit) by power plant and month

\begin{tabular}{lccc}
\hline Variable & $\mathbf{( 1 )}$ & $\mathbf{( 2 )}$ & $\mathbf{( 3 )}$ \\
\hline probsue*threat & $-0.392^{* * *}$ & $-0.400^{* * *}$ & $-0.412^{* * *}$ \\
& $(0.076)$ & $(0.075)$ & $(0.073)$ \\
lawsuit*action & $-0.194 * * *$ & $-0.200^{* * *}$ & $-0.209^{* * *}$ \\
& $(0.064)$ & $(0.064)$ & $0.077)$ \\
ln(gen) & $1.008^{* * *}$ & $1.150^{* * *}$ & $1.357^{* * *}$ \\
& $(0.101)$ & $0.129)$ & $(0.182)$ \\
Plant fixed effects & & & \\
Month-year fixed effects & Yes & Yes & Yes \\
Instrument for lawsuit & probsue & probsue & RHS vars \\
Instrument for ln(gen) & $\mathrm{No}$ & Yes & Yes \\
Observations & 6029 & 6029 & 6029 \\
$\mathrm{R}^{2}$ & 0.90 & 0.90 & 0.89 \\
First stage, lawsuit (P-value) & 0.001 & 0.001 & 0.001 \\
First stage, ln(gen) (P-value) & $\mathrm{n} / \mathrm{a}$ & 0.001 & 0.001 \\
Sargan overid test (P-value) & $\mathrm{n} / \mathrm{a}$ & 0.938 & 0.001 \\
\hline \hline
\end{tabular}

Notes: Robust (Newey-West) standard errors with 6-month lag structure. We use the Murphy-Topel correction for the generated regressor (probsue). We note significance at the 1-percent level $(* * *), 5$-percent level $(* *)$, and 10-percent level $(*)$. 


\section{Table V: Falsification Tests of Emissions Response}

Dependent variable: $\ln ($ emit $)$ by power plant and month

\begin{tabular}{lcc}
\hline Variable & $\mathbf{1 9 9 7}$ & $\mathbf{1 9 9 8}$ \\
\hline probsue*threat & 0.095 & -0.112 \\
& $(0.071)$ & $(0.071)$ \\
& & \\
lawsuit* action & -0.058 & -0.091 \\
& $(0.059)$ & $(0.058)$ \\
ln(gen) & & \\
& $1.103 * * *$ & $1.096 * * *$ \\
& $(0.119)$ & $(0.117)$ \\
Plant fixed effects & & \\
Month-year fixed effects & Yes & Yes \\
Instrument for lawsuit & probsue & probsue \\
Instrument for ln(gen) & Yes & Yes \\
Observations & 6029 & 6029 \\
$\mathrm{R}^{2}$ & 0.90 & 0.90 \\
First stage, lawsuit (P-value) & 0.001 & 0.001 \\
First stage, ln(gen) (P-value) & 0.001 & 0.001 \\
Sargan overid test (P-value) & 0.868 & 0.863 \\
\hline \hline
\end{tabular}

Notes: Robust (Newey-West) standard errors with 6-month lag structure. We use the Murphy-Topel correction for the generated regressor (probsue). We note significance at the 1-percent level $(* *), 5$-percent level $(* *)$, and 10-percent level $(*)$. 
Table VI: Regulatory Response to Changing Emissions

\begin{tabular}{|c|c|c|c|}
\hline Variable & $\begin{array}{r}(1) \\
\text { lawsuit (0/1) }\end{array}$ & $\begin{array}{r}(2) \\
\text { Demit99 }\end{array}$ & $\begin{array}{r}(3) \\
\text { lawsuit (0/1) }\end{array}$ \\
\hline$\overline{\Delta \ln (\text { emit })}$ & $\begin{array}{l}-0.0668 \\
(0.6248)\end{array}$ & & $\begin{array}{c}3.4294 * * * \\
(0.2424)\end{array}$ \\
\hline$m x \Delta e m i t$ & $\begin{array}{l}0.0580 * * * \\
(0.0147)\end{array}$ & $\begin{array}{l}-0.0051 * * \\
(0.0022)\end{array}$ & $\begin{array}{l}0.0305 * * * \\
(0.0118)\end{array}$ \\
\hline cum $\Delta$ emit & $\begin{array}{l}0.0058 * * \\
(0.0028)\end{array}$ & $\begin{array}{c}0.0005 \\
(0.0004)\end{array}$ & $\begin{array}{l}-0.0003 \\
(0.0019)\end{array}$ \\
\hline$m x \Delta g e n$ & $\begin{array}{l}-0.0002 \\
(0.0002)\end{array}$ & $\begin{array}{c}0.0000 \\
(0.0000)\end{array}$ & $\begin{array}{l}-0.0001 \\
(0.0001)\end{array}$ \\
\hline cum $\Delta g e n$ & $\begin{array}{c}0.0001 \\
(0.0001)\end{array}$ & $\begin{array}{c}0.0000 \\
(0.0000)\end{array}$ & $\begin{array}{c}0.0000 \\
(0.0001)\end{array}$ \\
\hline mxinvest & $\begin{array}{c}0.0008 \\
(0.0013)\end{array}$ & $\begin{array}{c}0.0000 \\
(0.0002)\end{array}$ & $\begin{array}{c}0.0001 \\
(0.0008)\end{array}$ \\
\hline mninvest & $\begin{array}{c}0.0252 * \\
(0.0133)\end{array}$ & $\begin{array}{l}-0.0004 \\
(0.0017)\end{array}$ & $\begin{array}{c}0.0086 \\
(0.0082)\end{array}$ \\
\hline mxmaint & $\begin{array}{l}-0.0288 \\
(0.0309)\end{array}$ & $\begin{array}{c}0.0009 \\
(0.0024)\end{array}$ & $\begin{array}{l}-0.0117 \\
(0.0121)\end{array}$ \\
\hline mnmaint & $\begin{array}{l}-0.0277 \\
(0.0478)\end{array}$ & $\begin{array}{l}-0.0041 \\
(0.0046)\end{array}$ & $\begin{array}{c}0.0119 \\
(0.0200)\end{array}$ \\
\hline $\ln ($ age $)$ & $\begin{array}{l}1.0770 * * \\
(0.5353)\end{array}$ & $\begin{array}{l}-0.0028 \\
(0.0711)\end{array}$ & $\begin{array}{c}0.2212 \\
(0.3148)\end{array}$ \\
\hline attainment & $\begin{array}{l}-0.5383 \\
(0.4953)\end{array}$ & $\begin{array}{l}0.2027 * * * \\
(0.0609)\end{array}$ & $\begin{array}{l}-0.7888 * * * \\
(0.2482)\end{array}$ \\
\hline damages & $\begin{array}{l}-0.0761 \\
(0.0718)\end{array}$ & $\begin{array}{l}-0.0003 \\
(0.0104)\end{array}$ & $\begin{array}{l}-0.0206 \\
(0.0419)\end{array}$ \\
\hline $\ln ($ plantsize $)$ & $\begin{array}{c}0.4878 * \\
(0.2685)\end{array}$ & $\begin{array}{c}0.0124 \\
(0.0337)\end{array}$ & $\begin{array}{c}0.0724 \\
(0.1497)\end{array}$ \\
\hline $\ln ($ firmsize $)$ & $\begin{array}{l}0.4391 * * * \\
(0.1484)\end{array}$ & $\begin{array}{c}0.0280 \\
(0.0183)\end{array}$ & $\begin{array}{c}0.0218 \\
(0.1023)\end{array}$ \\
\hline$\Delta \ln ($ sales $)$ & & $\begin{array}{l}0.6470 * * \\
(0.3010)\end{array}$ & \\
\hline constant & $\begin{array}{l}-5.6071 * * * \\
(2.0165)\end{array}$ & $\begin{array}{l}-0.0228 \\
(0.2591)\end{array}$ & $\begin{array}{l}-1.1472 \\
(1.3035)\end{array}$ \\
\hline Pseudo $\mathrm{R}^{2}$ & 0.40 & 0.10 & 0.43 \\
\hline
\end{tabular}

Notes: 249 observations. We note significance at the 1-percent level (***), 5-percent level $(* *)$, and 10-percent level $(*)$. Hausman tests reject that the coefficients of column 1 $\left(\chi^{2}=0.01\right.$, prob $>10$ percent $)$ or of column $3\left(\chi^{2}=9.6\right.$, prob $>10$ percent $)$ significantly differ from those in Table III. 
Table VII: Robustness Test using Three-Stage Least Squares

Dependent variable: Indicator of power plant named in lawsuit (0/1)

\begin{tabular}{|c|c|c|}
\hline Variable & Coefficient & Std. err \\
\hline$\Delta \ln ($ emit $)$ & 1.4551 & $0.5820 * *$ \\
\hline$m x \Delta e m i t$ & 0.0187 & $0.0060 * * *$ \\
\hline cum $\Delta$ emit & 0.0006 & 0.0009 \\
\hline$m x \Delta g e n$ & -0.0001 & 0.0001 \\
\hline cum $\Delta g e n$ & 0.0000 & 0.0000 \\
\hline mxinvest & 0.0007 & 0.0004 \\
\hline mninvest & 0.0018 & 0.0032 \\
\hline mxmaint & -0.0029 & 0.0071 \\
\hline mnmaint & -0.0053 & 0.0130 \\
\hline $\ln ($ age $)$ & 0.1265 & 0.1743 \\
\hline attainment & -0.0538 & 0.1693 \\
\hline damages & 0.0016 & 0.0245 \\
\hline $\ln ($ plantsize $)$ & 0.0731 & 0.0771 \\
\hline $\ln ($ firmsize $)$ & 0.0842 & $0.0404 * *$ \\
\hline constant & -0.4293 & 0.6279 \\
\hline
\end{tabular}

Dependent variable: Change in $\ln ($ emit) from Oct 97-Sep 98 to Oct 98-Sept 99

\begin{tabular}{lrc}
\hline Variable & Coefficient & Std. err \\
\hline lawsuit & -0.1461 & $0.0829 *$ \\
$\Delta \ln ($ gen $)$ & 1.5075 & $0.3113^{* * *}$ \\
constant & -0.0291 & 0.0317 \\
\hline \hline
\end{tabular}

Dependent variable: Change in $\ln ($ gen $)$ from Oct 97-Sep 98 to Oct 98-Sept 99

\begin{tabular}{lrr}
\hline Variable & Coefficient & Std. err \\
\hline$\Delta \ln (h d d)$ & 0.0243 & 0.1469 \\
$\Delta \ln ($ cdd $)$ & 0.1541 & 0.1028 \\
$\Delta \ln ($ sales $)$ & 0.2810 & 0.3010 \\
constant & 0.0196 & 0.0371 \\
\hline \hline
\end{tabular}

Notes: 102 "Table A plant" observations. We note significance at the 1-percent level $(* * *)$, 5-percent level $(* *)$, and 10-percent level $(*)$. 